\title{
IMPLEMENTASI METODE WEIGHT PRODUCT DALAM PENENTUAN KLASIFIKASI KELAS TUNAGRAHITA
}

\author{
Ayu Mira Yunita ${ }^{1}$, Ervi Nurafliyan Susanti ${ }^{2}$, Robby Rizki ${ }^{3}$ \\ 1,2,3 Jurusan Sistem Informasi Fakultas Teknologi dan Informatika Universitas Mathla'ul Anwar \\ Jln. Raya Labuan KM.23 - Cikaliung Saketi Pandeglang \\ ${ }^{1}$ ayumira@unmabanten.ac.id
}

\begin{abstract}
Abstrak - Tidak ada seorang anak yang ingin di lahirkan dengan berkebutuhan khusus, dan tidak ada orang tua yang menghendaki anak nya lahir dengan berkebutuhan khusus dan tidak ada satu orang tua pun yang mampu menolak anak berkebutuhan khusus.. Di Sekolah berkebutuhan khusus Al-Karim Cikedal mempunyai kerbatasan ahli psikologi dan sumber daya dalam menangani orang tua yang ingin berkonsultasi mengenani gangguan perkembangan anak pada saat pendaftaran sekolah dan bagaimana pihak sekolah memberikan keputusan mengenai penenpatan kelas pada anak. Tujuan Penelitian ini adalah membantu pihak sekolah dalam penentuan klasifikasi kelas Tunagrahita agar siswa betul-betul masuk pada kelas yang sesuai dengan kebutuhannya. Metode dalam penelitian ini menggunakan metode Weight Product berdasarkan empat kriteria yaitu kemampuan kognitif, bahasa, motorik dan social. Hasil dari penelitian ini adalah sebuah aplikasi sistem pendukung keputusan yang dapat membantu pihak sekolah dalam penentuan klasifikasi kelas bagi siswa Tunagrahita.
\end{abstract}

Kata Kunci - SPK, Tunagrahita, SKH, Penentuan, Weight Product.

\section{Pendahuluan}

Anak Berkebutuhan Khusus (ABK) merupakan anak yang terkena disfungsi otak. Disfungsi otak merupakan istilah umum yang digunakan untuk menyatakan akibat dari adanya cedera atau kerusakan, kelaianan perkembangan gangguan keseimbangan biokomiawi atau gangguan aktifitas listik dalam otak[1]. Anak berkebutuhan khusus adalah yang mengalami hambatan fisik dan mental sehingga menggangu pertumbuhan dan perkembangannya secara wajar yang memerlukan penanganan secara khusus. Anak yang termasuk dalam kategori berkebutuhan khusus salah satunya adalah tunagrahita (Retadarsi mental) [2]. Anak kelainan tunagrahita sangat berarti untuk memperoleh kesempatan yang sama dengan yang diberikan kepada anak normal lainnya dalam hal pendidikan dan pengajaran. Memberikan kesempatan yang sama kepada anak berkelainan untuk memperoleh pendidikan dan pengajaran, berarti memperkecil kesenjangan angka partisipasi pendidikan anak normal dengan anak berkelainan. Retardasi mental (Tuna Grahita) merupakan suatu keadaan perkembangan mental yang terhenti atau tidak lengkap yang ditandai oleh adanya cacat keterampilan selama masa perkembangan, sehingga berpengaruh pada semua tingkat intelegensi yaitu kemampuan kognitif, bahasa, motorik dan sosial. Tuna Grahita terbagi menjadi 3 kelas yaitu retardasi mental ringan, retardasi mental sedang dan retardasi mental berat. Mengetahui klasifikasi seorang anak tunagrahita tentunya bukan hal yang mudah karena harus mempelajari tingkah laku pada anak, demikian pula yang dialami oleh SKH AL-Karim Cikedal. Semua guru harus melakukan obsevasi agar bisa menentukan hasil klasifikasi, sehingga yang dibutuhkan oleh pihak sekolah adalah seorang psikolog. Studi kasus yang saya ambil di SKH AL-Karim Cikedal ini masih kekurangan sumber tenaga psikolog. Sistem Pendukung Keputusan merupakan sistem informasi interaktif yang menyediakan informasi, permodelan, dan pemanipulasian data. Sistem ini digunakan untuk membantu pengambilan keputusan dalam situasi yang semiterstruktur dan situasi yang tidak terstruktur, dimana tak seorang pun tahu secara pasti bagaimana keputusan seharusnya buat[3]. Implementasi sistem pendukung keputusan untuk aplikasi klasifikasi tunagrahita ini dilatar belakangi dengan keterbatasan ahli psikologi dan sumber daya SKH AL-Karim Cikedal mempunyai masalah yaitu dalam menangani orang tua siswa yang ingin berkonsultasi mengenai gangguan perkembangan anak pada saat pendaftaran sekolah dan bagaimana pihak sekolah memberikan keputusan mengenai penempatan kelas pada anak. Apakah masuk ke dalam kelas retardasi mental ringan, retardasi mental sedang atau retardasi mental berat, namun karena keterbatasan ini 
sementara pihak sekolah tidak dapat melayani konsultasi orang tua mengenai gangguan perkembangan pada anaknya.Setiap penderita kelainan tunagrahita membutuhkan informasi mengenai gejala dan jenis kelainan tunagrahita. Penulisan pada sistem pendukung keputusan dengan menggunakan metode Weight Product (WP). WP merupakan salah satu metode multi cretia decision making (MCDM). MCDM merupakan tehnik pengambilan keputusan dari beberapa pilihan alternative yang ada [4]. untuk kelainan tunagrahhita ini dimulai dari pengumpulan data, klasifikasi kelainan dan terakhir penentuan kelas dari kelainan itu sendiri. Gangguan kelainan ini pada anak Tunagrahita seringkali merepotkan para orang tua dikarnakan kurangnya pengetahuan tentang kelainan tersebut, oleh karena itu diperlukan suatu sistem yang dapat digunakan untuk semua guru agar dapat menginputkan data siswa yang berkelainan Tuna Grahita dan menyimpannya untuk jangka waktu yang panjang. Sistem pada tunagrahita ini dapat diketahui dari jenis kelainan yang ada dan dapat mencegah timbulnya kelainan ganda. Data-data berupa jenis kelainan tersebut nantinya akan digunakan untuk menjawab pertanyaan yang menyangkut penentuan jenis gangguan tunagrahita, sehingga sistem pendukung keputusan ini dapat memberikan kemudahan dalam membantu semua guru untuk menentukan kelainan Tuna Grahita.

\section{Metodologi Penelitian}

A. Model Pengembangan system Informasi

Model Pengembangan system informasi pada penelitian ini menggunkan metode waterfall atau biasa di sebut dengan metode air terjun, dimana hal ini menggambarkan pendekatan yang sistematis dan juga berurutan pada pengembangan perangkat lunak, dimulai dengan spesifikasi kebutuhan pengguna lalu berlanjut melalui tahapan - tahapan perencanaan, permodelan, konstruksi, serta penyerahan system ke pelanggan /pengguna yang diakhiri dengan dukungan perangkat lunak lengkap yang dihasilkan. Tahapan metode waterfall dapat dilihat pada gambar di bawah ini. [5]

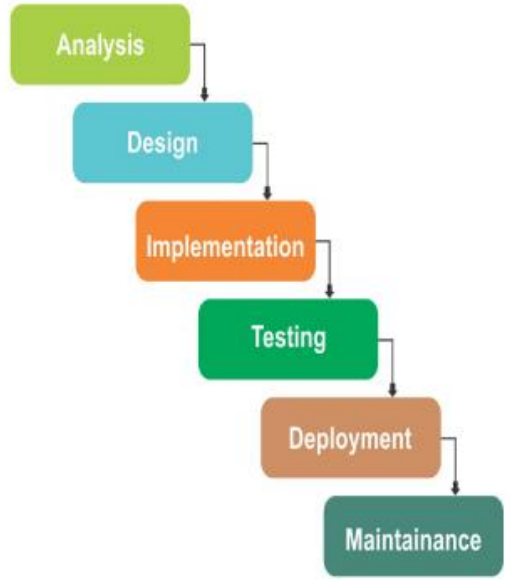

Gambar. 1 Tahapan metode waterfall

\section{B. Metode Pengumpulan data}

Metode pengumpulan data merupakan langkah yang paling strategis dalam penulisan, karena tujuan utama dari penulisan adalah mendapatkan data.

1. Metode Wawancara (Interview)

Salah satu teknik pengumpulan data yang penulis lakukan yaitu dengan cara tanya jawab secara langsung kepada koordinator psikologi Tuna Grahita di SKH AlKarim Cikedal selaku psikologi dengan kajian yang sudah disusun sehingga memperoleh data yang relevan untuk menunjang penulisan yang berkaitan dengan topik yang diambil, yakni tentang Sistem Pendukung Keputusan penentuan Klasifikasi Tuna Grahita dengan Metode.

2. Metode observasi (pengamatan langsung)

Salah satu teknik yang penulis gunakan pula yakni dengan melihat secara langsung bagaimana proses pembagian pembelajaran anak tunagrahita yang sedang berlangsung di SKH Al-Karim Cikedal.

3. Metode kepustakaan

Teknik yang terakhir yakni dengan cara mempelajari, meneliti,serta menelaah berbagai literatur dari beragam sumber mulai dari buku-buku, jurnal ilmiah, situs internet, dan media-media lainnya yang berkaitan dengan penulisan yang dilakukan.

C. Analisa system yang berjalan

Sistem ini menjelaskan mengenai analisis system yang sedang berjalan, yaitu tentang kegiatan atau arus dokumen penentuan klasifikasi tuna grahita.

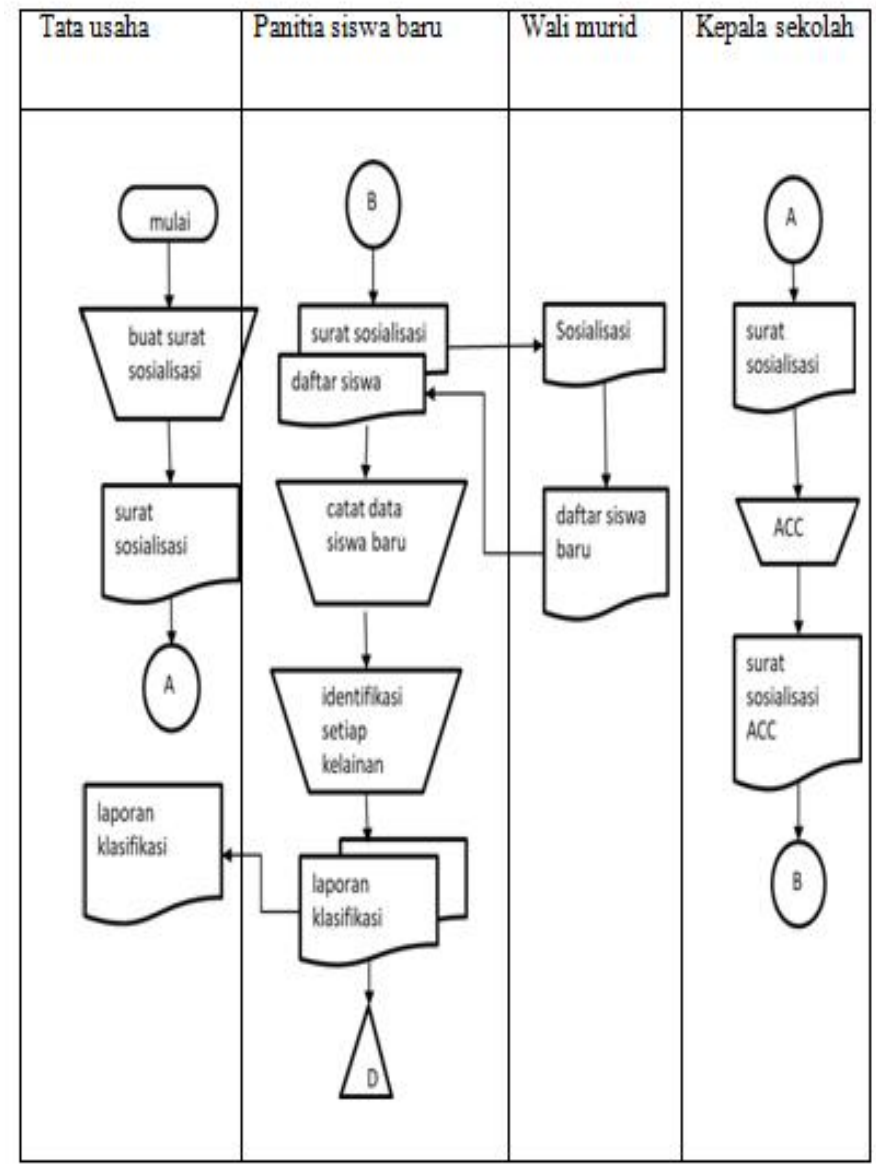


Gambar. 2 Analisis system yang berjalan.

D. Metode Weight Product

Salah satu metode untuk menyelesaikan sistem pendukung keputuan adalah weight product, dimana metode ini berkerja berdasarkan besarnya nilai referensi yang dihitung berdasarkan nilai variable. Yang digunakan yang dipangkatkan dengan bobotnya. Semakin besar nilai presentasi suatu alternatif solusi maka alternatif solusi itu semakin disukai. Besarnya nilai preferensi dihitung dengan formula sebagai berikut [6]:

$$
S_{i}=\prod_{j=1}^{n} x_{i j} w_{j}
$$

Keterangan:

$$
S_{i}=\prod_{j=1} x_{i j}
$$

S : Menyatakan preferensi alternatif yang dianalogikan sebagai vector $S$

$\mathrm{X}$ : Menyatakan nilai Kriteria

$\mathrm{W}$ : Menyatakan bobot kriteria

i : Menyatakan alternatif

j : Menyatakan kriteria

$\mathrm{n}$ : Menyatakan banyaknya kriteria

Hasil perkalian tersebut dijumlahkan untuk menghasilkan nilai vektor $\mathrm{V}$ untuk setiap alternatif. Nilai vektor $\mathrm{V}$ dapat dihitung dengan rumus:

$$
V_{i}=\frac{\prod_{j=1}^{n} x_{i j}{ }^{w_{j}}}{\prod_{j=1}^{n}\left(x_{j}\right)^{w_{j}}}
$$

Keterangan:

$\mathrm{V}$ : Menyatakan preferensi alternatif yang dianalogikan sebagai vectorV

$\mathrm{X}$ : Menyatakan nilai Kriteria

w : Menyatakan bobot kriteria

i : Menyatakan alternatif

j : Menyatakan kriteria

$\mathrm{n}$ : Menyatakan banyaknya kriteria

\section{HASIL DAN PEMBAHASAN}

Hasil dari penelitian yang dilakukan akan di jelaskan sebagai berikut :

A.

\section{Analisis Perhitungan weight Product}

\section{Penentuan Nilai Bobot W (Kriteria)}

Dalam penentuan klasifikasi kelas tuna grahita, terdapat beberapa kriteria yang bisa menjadi acuan sebagai bahan pertimbangan pengklasifikasian, di sampel penelitian terdapat: terdapat tiga puluh siswa yang masing-masing mempunyai kelainan yang berbeda, untuk mendapatkan hasilnya, terlebih dahulu dilakukan perbaikan bobot, perbaikan bobot menggunakan rumus $W j$.

Maka dihitung sebagai berikut:

1. Kriteria yang digunakan sebagai acuan adalah:
Tabel .1 Kriteria Penilaian

\begin{tabular}{l|c}
\hline Kriteria penilaian & Bobot \\
\hline Kognitif & 1 \\
\hline Bahasa & 2 \\
\hline Motorik & 3 \\
\hline Sosial & 4 \\
\hline
\end{tabular}

2. Pengambilan keputusan memberikan bobot referensi sebagai berikut: $\mathrm{W}=(3+4+5+3)$ jumlah $=15$

3. Sebelumnya dilakukan perbaikan bobot terlebih dahulu maka pangkat diperoleh dari julah $\mathrm{w}$ dibagi masingmasing nilai dari kriteria yang sudah ditentukan dan hasilnya adalah:

$$
\begin{aligned}
& W_{1}=\frac{3}{3+4+5+3}=0,2 \\
& \ldots \ldots \ldots 3 \\
& W_{2}=\frac{4}{3+4+5+3}=0,27 \\
& W_{3}=\frac{5}{3+4+5+3}=0,33 \\
& W_{4}=\frac{3}{3+4+5+3}=0,2
\end{aligned}
$$

$$
\sum \mathrm{w}=0,2+0,27+0,3+0,2=1
$$

Tabel .2 Nilai Kriteria

\begin{tabular}{l|l|l}
\hline Nama_Kriteria & Bobot & Perbaikan Bobot \\
\hline Kognitif & 3 & 0,2 \\
\hline Bahasa & 4 & 0,27 \\
\hline Motorik & 5 & 0,33 \\
\hline Sosial & 3 & 0,2 \\
\hline
\end{tabular}


2. Pemberian Bobot Alternatif

Dibawah ini penulis paparkan pemberian bobot kesetiap anak yang memiliki kelainan Tuna grahita untuk masing-masing kriteria:

Tabel 3 Pemberian Bobot Alternatif

\begin{tabular}{l|l|c|c|l|l}
\hline No & Nama siswa & $\mathrm{Kg}$ & $\mathrm{Bh}$ & $\mathrm{Mt}$ & $\mathrm{Ss}$ \\
\hline 1 & $\begin{array}{l}\text { Sifa } \\
\text { Nurpadilah }\end{array}$ & 60 & 60 & 60 & 70 \\
\hline 2 & Siti Julaeha & 80 & 70 & 70 & 70 \\
\hline 3 & $\begin{array}{l}\text { Adeng } \\
\text { Suryana }\end{array}$ & 30 & 40 & 60 & 60 \\
\hline 4 & Aulia Syifa & 70 & 70 & 70 & 60 \\
\hline 5 & $\begin{array}{l}\text { Samsul } \\
\text { Hidayat }\end{array}$ & 60 & 70 & 70 & 60 \\
\hline 6 & Dian Irawan & 40 & 30 & 40 & 50 \\
\hline
\end{tabular}

Keterangan:

$\begin{array}{ll}\mathrm{Kg} & : \text { Kognitif } \\ \mathrm{Bh} & : \text { :Bahasa } \\ \mathrm{Mt} & \text { :Motorik } \\ \mathrm{Ss} & \text { :Sosial }\end{array}$

3. Menghitung Nilai Vektor Si

Kemudian langkah selanjutnya adalah menghitung vector $\mathrm{S}$, dimana data akan dikalikan, tetapi sebelumnya dilakukan pemangkatan dengan bobot dari:

Sifa Nurfadilah $=$

$\left(60^{0,2}\right)\left(60^{0,27}\right)\left(60^{0,3}\right)\left(70^{0,2}\right)$

$=2,26793 \times 3,02065 \times 3,41543 \times 2,33894$

$=61,879$

Siti Julaeha

$=\left(80^{0,2}\right)\left(70^{0,27}\right)\left(70^{0,3}\right)\left(70^{0,2}\right)$

$=2,40225 \times 3,14903 \times 3,57709 \times 2,33894$

$=71,895$

Adeng Suryana

$=\left(30^{0,2}\right)\left(40^{0,27}\right)\left(60^{0,3}\right)\left(60^{0,2}\right)$
$=1,97435 \times 2,70742 \times 3,41543 \times 2,26793$

$=46,817$

Aulia Syifa

$=\left(70^{0,2}\right)\left(70^{0,27}\right)\left(70^{0,3}\right)\left(60^{0,2}\right)$

$=2,33894 \times 3,14903 \times 3,57709 \times 1,97435$

$=64,875$

Samsul Hidayat

$=\left(60^{0,2}\right)\left(70^{0,27}\right)\left(70^{0,3}\right)\left(60^{0,2}\right)$

$=2,26793 \times 3,14903 \times 3,57709 \times 2,26793$

$=65,814$

Dian Irawan

$=\left(40^{0,2}\right)\left(30^{0,27}\right)\left(40^{0,3}\right)\left(50^{0,2}\right)$

$=2,09128 \times 2,50509 \times 3,02425 \times 2,18672$

$=38,7$

4. Menghitung nilai bobot preferensi pada setiap alternatif (Nilai Vaktor Vi)

Setelah nilai vektor $\mathrm{S}$ didapat, maka selanjutnya adalah menjumlahkan seluruh vektor $\mathrm{S}$ untuk menghitung vektor $\mathrm{V}$, perhitungannya sebagai berikut:

$\mathrm{Vi}=61,879+71,895+46,817+67,875+65,814+38,7$

$\mathrm{Vi}=352,98$

Sifa Nurpadilah $=\frac{61,879}{352,98}=0,1753$

Siti Julaeha

$$
=\frac{71,895}{352,98}=0,20368
$$

Adeng Suryana $=\frac{46,817}{352,98}=0,13263$

Aulia Syifa

$$
=\frac{67,875}{352,98}=0,19229
$$

Samsul Hidayat

$$
=\frac{65,814}{352,98}=0,18645
$$

Dian Irwan

$$
=\frac{38,7}{352,98}=0,10964
$$

5. Melakukan laporan 
Tabel 4 laporan hasil

\begin{tabular}{|c|c|c|c|}
\hline No & $\begin{array}{l}\text { Nama } \\
\text { Alternatif }\end{array}$ & $\begin{array}{l}\text { Nilai } \\
\text { Bobot } \\
\text { Preferensi } \\
\text { (Vi) }\end{array}$ & Keterangan \\
\hline 1 & $\begin{array}{l}\text { Sifa } \\
\text { Nurpadilah }\end{array}$ & 0,1753 & $\begin{array}{l}\text { Klasifikasi } \\
\text { Kelas } \\
\text { Sedang }\end{array}$ \\
\hline 2 & Siti Julaeha & 0,20368 & $\begin{array}{l}\text { Klasifikasi } \\
\text { Kelas } \\
\text { Ringan }\end{array}$ \\
\hline 3 & $\begin{array}{l}\text { Adeng } \\
\text { Suryana }\end{array}$ & 0,13263 & $\begin{array}{l}\text { Klasifikasi } \\
\text { Kelas Berat }\end{array}$ \\
\hline 4 & Aulia Syifa & 0,19229 & $\begin{array}{l}\text { Lasifikasi } \\
\text { Kelas } \\
\text { Ringan }\end{array}$ \\
\hline 5 & $\begin{array}{l}\text { Samsul } \\
\text { Hidayat }\end{array}$ & 0,18645 & $\begin{array}{l}\text { Klasifikasi } \\
\text { Kelas } \\
\text { Ringan }\end{array}$ \\
\hline 6 & Dian Irawan & 0,10964 & $\begin{array}{l}\text { Klasifikasi } \\
\text { Kelas Berat }\end{array}$ \\
\hline
\end{tabular}

Keterangan:

Dari $0,18-1,00=$ Tuna Grahita Ringan

Dari $0,15-0,17=$ Tuna Grahita Sedang

Dari 0,11- 0,13 = Tuna Grahita Berat

\section{KESIMPULAN}

Telah dilakukan penelitian menggunakan metode weight product dapat digunakan untuk membantu pihak sekolah dalam menentukan klasifikasi kelas untuk siswa berdasarkan kriteria yang telah di tentukan.

\section{REFERENSI}

[1] D. Susandi and H. L. Anita, (2019 )"Keputusan Pemilihan Supplier Menggunakan Metode Simple," vol. 6, no. 2, pp. 79-85,

[2] D. Winarso, F. Nurita, and S. Syahril, (2018). "Penerapan Metode Weigth Product Untuk Rekomendasi Penempatan Praktek Kerja Industri (Study Kasus: SMK Muhammadiyah 01 Pekanbaru)," J. RESTI (Rekayasa
Sist. dan Teknol. Informasi), vol. 2, no. 2, pp. 566-571, doi: 10.29207/resti.v2i2.467.

3] H. Rhomadhona, "Rancang Bangun Sistem Pakar Diagnosa Karakteristik Anak Berkebutuhan Khusus Menggunakan Metode Forward Chaining," J. Sains dan Inform., vol. 3, no. 1, p. 18, 2017, doi: 10.34128/jsi.v3i1.66.

4] H. Supriyono, (2015). "Pemilihan Rumah Tinggal Menggunakan Metode Weighted Product," Khazanah Inform. J. Ilmu Komput. dan Inform., vol. 1, no. 1, p. 23, doi: 10.23917/khif.v1i1.1178.

5] P. Arsi and Y. Novita, (2018). "Sistem Pendukung Keputusan Penilaian Perkembangan Anak Berkebutuhan Khusus Tuna Grahita Menggunakan Metode Weighted Product," J. ICT Inf. Commun. Technol., vol. 17, no. 2, pp. 48-52, , doi: 10.36054/jict-ikmi.v17i2.34.

6] Y. Perwira, (2019). "Penentuan Peringkat Pelanggan Terbaik Dengan Metode Weighted Product ( Studi Kasus Pt . Asia Raya Foundry ),” vol. 3, no. 1, pp. 138-147. 